\title{
Periodismo en contextos de violencia. Aproximaciones en México y el País Vasco: similitudes y diferencias en procesos de conflicto inacabados
}

\author{
Gabriel A. Corral Velázquez ${ }^{1 *}$
}

\begin{abstract}
Resumen
La violencia, en cualquiera de sus conceptualizaciones, representa agresiones que no permiten el pleno ejercicio de derechos. El análisis que se ofrece es un comparativo de las particularidades en la práctica periodística en dos países, México y el País Vasco. Se presenta un contexto histórico que relata los acontecimientos más significativos de la historia de cada país y de la historia de la prensa en ambos entornos, relato articulado con similitudes y divergencias que persisten en virtud de los episodios de violencia que se han padecido en ambos países. Luego, con entrevistas a profesionales del periodismo se ilustra el contexto reseñado señalando las particularidades de cada caso.

Abstract

Violence, in any of its conceptualizations, represents aggressions that do not allow the full exercise of rights. The analysis offered is a comparison of the particularities of journalistic practice in two countries, Mexico and the Basque Country. It presents a historical context that recounts the most significant events in the history of each country and the history of the press in both environments, a story articulated with similarities and divergences that persist in virtue of the episodes of violence that have been suffered in both countries. Then, with interviews to professionals of journalism the outlined context is illustrated pointing out the particularities of each case.
\end{abstract}

\section{Palabras Clave}

Violencia, Libertad de expresión, Periodismo, Conflicto

Keywords

Violence, Freedom of speech, Journalism, Conflict

${ }^{1}$ Doctor en Estudios Científico Sociales. Universidad Autónoma de Querétaro, México.

*Autor para correspondencia: corral@uaq.mx

\section{El contexto histórico en Euskadi}

Geográficamente el territorio del País Vasco ${ }^{1}$ se encuentra dividido por los pirineos: en la península ibérica conformada hoy en día por las provincias de Araba, Bizkaia y Guipuzkoa y la comunidad foral de Navarra y en el Estado Francés por las provincias de Zuberoa, Behe Nafarroa y Lapurdi. El origen del Pueblo Vasco se remonta a la época prehistórica

\footnotetext{
${ }^{1}$ Euskadi fue el nombre que Sabino Arana utilizó a finales del S. XIX como una derivación castellana de Euskal Herria (Pueblo Vasco) está aceptado utilizar de manera indistinta ambas o el nombre castellano País Vasco. En este documento se utilizarán de igual forma las tres.
}

y posteriormente, como país con la conformación del Reino de Navarra al mismo tiempo que se daban los conflictos y guerras de unificación con el Reino de Castilla, Reino de León o Asturias, en la edad media.

En su configuración política es relevante la organización que se dio a partir del sistema de fueros ${ }^{2}$. Los cuales marcaron de manera particular la autonomía con la que el Pueblo Vasco organizó su vida social y política. Este sistema foral permitía, aun perteneciendo al Reino de Castilla o Navarra, establecer

\footnotetext{
${ }^{2}$ El término fuero no refiere a privilegios como se conoce de manera cotidiana el fuero; en euskera, se refiere a las leyes Foru - Forua (ley en euskera).
} 
de manera independiente leyes locales, impuestos y tribunales. Para Estornés (1976), las Instituciones Forales son “expresión de un proceso productivo y de unas relaciones de producción específicas, han constituido el medio histórico sobre el que flotaba y se mantenía la vida política vasca".

La autonomía del Pueblo Vasco ha sido reivindicada en diversos procesos históricos, siempre señalando al sistema foral como constitutiva de su organización social y política. De los siglos XVI al XIX, las provincias del País Vasco (Araba -Álava-, Bizkaia y Guipozkoa) formaron parte del Reino de España manteniendo los fueros. Exploradores y navegantes vascos participaron durante la conquista de América y en expediciones de la Armada española y durante la guerra de independencia a inicios del S. XIX con la intervención francesa en la península en la época del imperio napoleónico.

Hacia mediados del siglo XIX se inició un periodo de guerras por motivos de sucesión en la corona de España. Las Guerras Carlistas para Euskal Herria resultaron especialmente convulsas por el interés de mantener el sistema foral. Sin embargo, al finalizar las guerras carlistas en 1876 se abolió este sistema, lo que implicó el primer gran golpe que recibe la autonomía del País Vasco:

La forma en que se produjo el acontecimiento -ocupación militar, ley marcial, censura de prensa, deportaciones, etc.- unida a la campaña antiforal del resto de la península (excepto Cataluña que apoyó siempre a los vascos) proyectó sobre Vasconia una ola de histérica agresividad, que marcó para siempre la conciencia del país (Estornés, 1976).

En los años posteriores surgió dentro de las Provincias Vascas y Navarra un sentimiento nacionalista que reivindicaba el restablecimiento de los fueros. A finales del siglo XIX Sabino Arana funda el Partido Nacionalista Vasco. En él aglutinó los reclamos de autonomía foral, lingüístico y étnicos.

Con el triunfo de la República en 1931 se establecieron nuevas formas de relación entre el gobierno vasco y el gobierno de España, se formuló un estatuto nuevo conocido como el Estatuto de Estella vigente a partir de 1936 con José Antonio Aguirre como Lehendakari. Con el inicio de la guerra civil española, el bando nacional, comandado por el general sublevado Francisco Franco, prohíbe todo tipo de autonomía y suprime el gobierno vasco. Desde ese momento se establecieron normativas que cierran la posibilidad de reivindicación cultural y lingüística. El gobierno autónomo vasco se estableció en el exilio desde entonces y hasta 1976.

Los años del franquismo fueron especialmente duros para Euskal Herria. Como en la mayoría de las comunidades españolas se establecieron gobiernos civiles y cualquier reivindicación opositora o nacionalista era sometida. La actividad política abertzale (nacionalista) se llevaba a cabo en la clandestinidad. En este contexto de prohibición y sometimiento, emerge en diversas capas de la sociedad vasca la necesidad de reivindicar la autonomía foral que había imperado en el país desde hacía siglos.

En 1959 se formó la organización ETA (Euskadi ta Askatasuna -País Vasco y Libertad) grupo político-insurgente que, a través de la lucha armada, promovió la conformación del País Vasco independiente unificando las siete provincias históricas vascas. Esta organización surge como rechazo a las prohibiciones sociales a las que fue sometido el País Vasco durante la dictadura de F. Franco. Ideológicamente de izquierda, ETA se autodefinía como grupo revolucionario socialista de liberación del pueblo vasco. A partir de 1968 inició su actividad armada, dando inicio al periodo denominado conflicto vasco (Ramírez de la Piscina, Murua,\& Idoiaga, 2016). El conflicto armado se desarrolló entre 1968 y 2011, año en el que ETA anunció su desarme (su disolución definitiva se daría en mayo de 2018).

Con la constitución de 1978 en el Estado Español se reestablecen los regímenes de autonomía, por años reivindicados por los diferentes gobiernos vascos. Pese al reconocimiento a través del estatuto de Gernika del régimen autónomo y foral, el conflicto vasco se recrudece llevando a años de intensa lucha armada y a un ejercicio periodístico sometido a violencia y presiones de muy diversa índole.

\section{Contexto histórico en México}

En México se puede construir el análisis histórico a partir de la estructuración del Estado como se le conoce ahora. Herencia de procesos de guerra civil e intervenciones extranjeras. Luego de la guerra de independencia en 1821, la guerra con Estados Unidos, la intervención francesa que culminó con el fusilamiento de Maximiliano en Querétaro y 
la República Restaurada, el estado mexicano se consolidó en régimen y leyes con el gobierno de Porfirio Díaz en 1876.

En el porfiriato se establecieron las dinámicas que rigieron las políticas sociales y económicas, se reafirmó el estado. En estos años, se modernizó el sistema de comunicaciones y se creó un modelo de régimen federal a partir del cual las entidades negociaban sus prioridades con el gobierno central.

Durante este periodo el estado estableció lo que podrían llamarse las reglas del juego y a través de ellas se administraron los recursos de forma adecuada, se estableció un control de ingresos, se creó un sistema recaudatorio que permitía el comercio y se reestructuró la deuda. En general, se modernizó el Estado. Sin embargo, por otra parte se profundizaron las desigualdades y el régimen de libertades políticas se restringió de tal forma que era nula la presencia opositora en los espacios de deliberación pública. El régimen porfiriano construyó una red de apoyos en las clases pudientes que le permitieron mantenerse por un periodo de treinta años.

Con la Revolución Mexicana de 1910 inició el periodo de reconfiguración del Estado. En la nueva constitución promulgada en 1917 se establecieron una serie de lineamientos que liberalizaron el país y se consignaron derechos producto de reclamos agrarios y obreros, los dos sectores más desfavorecidos por el régimen porfirista.

A partir de 1929, luego de un periodo de guerras civiles, se estableció el régimen de partido único con la fundación del Partido Nacional Revolucionario, a iniciativa de Plutarco Elías Calles. En él se aglutinaron todos los sectores herederos de la revolución y se institucionalizó el régimen que gobernó el país durante más de setenta años. El régimen permitió el establecimiento de políticas económicas y sociales que permitieron en un inicio la pacificación del país y, posteriormente, la estabilidad para el desarrollo económico. Con ello pudo emerger una clase media en las grandes ciudades y, con ella, el reclamo de libertades políticas.

A partir de 1968, sectores sociales e intelectuales aumentaron las voces disidentes que exigían la apertura democrática del régimen político. En los años setenta, con el surgimiento de grupos insurgentes en el sur y la capital del país, los hechos violentos reivindicativos se hicieron presentes.
Sin embargo, se destaca que la presión democratizadora del país provino no de los sectores desfavorecidos o de la lucha insurgente sino de la clase media acomodada del norte y centro. Producto de la crisis económica de inicios de los años ochenta y del descontento del sector empresarial, de la mano del Partido Acción Nacional iniciaron una serie de movilizaciones en defensa del voto en Chihuahua, San Luis Potosí y Guanajuato, principalmente.

A nivel nacional, la llamada Corriente Democrática dirigida por Cuauhtémoc Cárdenas, al interior del Partido Revolucionario Institucional (PRI), intentó modificar algunas prácticas políticas que prevalecían dentro de las estructuras del partido. Al no encontrar respaldo, se postuló como candidato a la presidencia de la república de 1988 por una coalición de partidos en la que, quizá, fue la primera elección competida del México posrevolucionario. Con el apoyo de los sectores populares, hizo frente al candidato del PRI; no obstante, una polémica decisión del Consejo Electoral lo marginó del triunfo.

Con el impulso democratizador de esos años y las reformas neoliberales que lo secundaron, durante la década de los noventa tuvieron lugar acontecimientos que es importante señalar porque anteceden al objetivo de este trabajo. En principio, la emergencia del Ejército Zapatista de Liberación Nacional, los asesinatos del cardenal Juan Jesús Posadas Ocampo, del candidato Luis Donaldo Colosio, y del secretario del PRI, José Francisco Ruiz Massieu; hechos de violencia que cimbraron las estructuras políticas y sociales en los años 1993 y 1994.

Con la reforma electoral de 1995 y 1996 se establecieron nuevas normativas con la mira puesta en la elección presidencial del año 2000, en la cual, por primera vez en setenta años, triunfaba un candidato de oposición. Con la alternancia electoral se abrieron retos y perspectivas que, al menos en el papel, presagiaban modificaciones a las estructuras políticas y gubernamentales. Dieciocho años después, con tres elecciones presidenciales y dos alternancias, se puede señalar que de fondo el sistema político mexicano ha cambiado muy poco, en lo institucional y prácticamente nada en cuanto a la cultura política.

La elección de 2006, polémica por la forma en cómo se dictaminó el resultado y por la desequilibrada cobertura y promoción de los candidatos, abrió una nueva página en los 
conflictos poselectorales. Con el triunfo de Felipe Calderón se puso en marcha el operativo Michoacán y lo que a la postre se llamó guerra contra el narcotráfico, que no era otra cosa que el arranque del Plan Mérida firmado entre el gobierno mexicano y los Estados Unidos.

Con la puesta en marcha del operativo Michoacán en diciembre de 2006, se abrió una de las páginas más violentas de la historia reciente de México.

\section{La práctica periodística en contexto de violencia}

La inseguridad y la violencia son dos temas recurrentes en cualquier conversación en México. La inseguridad ocupa el primer lugar en las preocupaciones de los mexicanos en los últimos doce años. La violencia, producto del fracaso de la guerra contra el narcotráfico iniciada en el sexenio de Felipe Calderón (2006 - 2012), al día de hoy se ha extendido por todo el país. 2017 ha sido el año más violento desde el año 2000, con una cifra que supera los 29 mil muertos.

En Euskal Herria, los años más duros del conflicto que llevaron a actos de violencia han pasado. En contraste con el caso de México, la violencia en el País Vasco estaba relacionada con reivindicaciones políticas e ideológicas, no con crimen organizado. La cifra de hechos violentos atribuidos a los grupos armados independentistas o de izquierdas se saldó con 837 muertes entre 1960 y 2013. Las fuerzas de seguridad del Estado contabilizaron 94 víctimas de este tipo y los grupos parapoliciales y de extrema derecha causaron 73 muertes (Carmena, Mirena, Múgica, \& Uriarte, 2013). Además, entre 1960 y 2014 se produjeron 4,113 casos de tortura en dependencias policiales (Etxeberria, Beristain, y Pego, 2017).

En ambos casos, los hechos de violencia también llegaron a los responsables de los medios de comunicación. Para Gómez y Rodelo, la violencia mediática refiere a "aquellos actos de agresión (en su mayoría intencionales) que se transmiten o publican en los medios de forma textual, sonora, gráfica o audiovisual" (2012, p. 321). Partiendo de esta definición y del contexto ofrecido, se puede señalar que en distintos momentos la violencia en contra del ejercicio periodístico o en los ataques a la libertad de expresión ha sido una forma de fragmentar o parcializar el conocimiento de los hechos que tienen lugar en una sociedad.
Las prácticas de control y violencia contra el ejercicio periodístico han sido una constante de los gobiernos a lo largo de la historia. En México, señala García Hernández (2000), desde el porfiriato se establecieron controles a las publicaciones y, de alguna manera, también se instauraron las reglas del juego entre los poderes políticos y el periodismo. Mientras que, en Euskadi, a inicios del siglo XX el periodismo fluctuó entre las dictaduras de Primo de Rivera y de Franco (con el paréntesis de la Segunda República entre 1931 y 1936). En este periodo el periodismo vasco sufrió de censuras como el resto del Estado español, fijando la perspectiva en una centralidad y control a las publicaciones.

Durante el periodo de la revolución mexicana, los cambios en las relaciones políticas y sociales, así como las luchas entre los diferentes bandos revolucionarios fueron reseñadas en las diversas publicaciones de la época.

Desde que Madero se levantó en armas hasta 1940, los periodistas mexicanos vivieron en un ambiente de razonable holgura, interrumpido brutalmente por la dictadura de Victoriano Huerta y la Guerra Cristera. Esta libertad se iría constriñendo desde 1929 con la formación del Partido Nacional Revolucionario (PNR) (Serna, 2014, p. 118)"

En las primeras décadas del S. XX el periodismo era muy apreciado puesto que suponía que

en medio del conflicto armado, el diario y su función informativa tuvieron un importante peso social como guía del público, instrumento de combate y, también, como peligrosos creadores de escándalo, rumor y — como decía Maderodel potencial para generar más violencia. Los periódicos de aquella época alardeaban de ser veraces y oportunos (Serna, 2014, p. 120).

Contrario a la Revolución Mexicana, la Guerra Civil en España supuso un atraso para el periodismo en el País Vasco. Las publicaciones periodísticas en euskera cuentan con más de cien años de historia. Se tienen reseñadas al menos tres publicaciones editadas al cien por ciento en 
euskera $^{3}$ : la primera fue Euskalzale, editada en 1896; le siguió el periódico Ibaizabal que comenzó su circulación en 1902; y posteriormente el histórico diario Eguna que vio cortada su publicación por la guerra en 1936, producto de las prohibiciones al euskera y a cualquier simbología cultural vasca por parte del bando nacional.

La política de control más cerrada en el Estado español se mantuvo de 1945 a 1966. En este periodo de veinte años, la dictadura franquista aplicó la censura a cualquier publicación que atentara contra "los principios fundamentales del Estado". Según Álvarez (2018, p. 7), este marco jurídico se mantuvo hasta que, dentro de las estructuras gubernamentales, se abrió la posibilidad de reformas en el mecanismo de control a la prensa en el año de 1966, dado que la ley de prensa e imprenta publicada en marzo de ese año liberalizó la censura y permitió que se hablara de temas hasta entonces prohibidos.

En el México posrevolucionario, el control del periodismo se llevó a cabo a través de concesiones políticas. La tesis que enmarca la relación entre el poder político y la prensa sostiene que el control del gobierno se estableció a través del monopolio del papel impuesto por la Productora e Importadora de Papel (PIPSA), empresa pública creada por Lázaro Cárdenas en 1935. Por medio del suministro de papel, el partido y el presidente en funciones tejieron una relación simbiótica que decantaría en un periodismo al servicio de los intereses de la administración en turno. En los 127 diarios y 673 revistas de todo género que circulaban en ese momento con influencia nacional, la norma era "la línea del Señor presidente" (Fuentes-Berain, 2001).

Este modelo estructural de relación subordinada de los medios al poder público en el México del siglo XX pasa por varias etapas que van del proceso de encuadramiento corporativo de todos los sectores socioeconómicos al Estado, a la integración del mencionado complejo político empresarial (o burocrático empresarial) de intereses comunes entre los sectores políticos y burocráticos y los de las grandes corporaciones empresariales, complejo cuyos engranes se han movido históricamente con el lubricante de la corrupción institucionalizada (Carreño, 2000).

\footnotetext{
${ }^{3}$ Se pueden consultar estas publicaciones en la Biblioteca de la Diputación Foral de Bizkaia http://www.bizkaia.eus/Kultura/Euskara/eguna/
}

El conflicto vasco inició en los años sesenta con la aparición de la organización ETA. En un periodo de cuarenta años, el conflicto protagonizó las portadas de diarios de ámbito estatal e internacional. Siempre señalando la violencia como el elemento central, el conflicto ha supuesto una serie de interpelaciones por parte de los protagonistas y una condicionante en el ejercicio periodístico en Euskal Herria.

La atención prestada por los medios de comunicación al conflicto vasco ha sido muy relevante durante las cuatro últimas décadas. Dos pueden ser los factores que explican esa macro-presencia en los medios: las dramáticas consecuencias del propio conflicto, derivadas en buena medida de su prolongación en el tiempo y la dimensión política del mismo. No hay que olvidar que el conflicto vasco afecta a una cuestión central del Estado como es su ordenamiento jurídico e interpela, además, sobre el depositario último de su soberanía nacional (Ramírez de la Piscina et al., 2016, p. 1008).

El entorno de violencia en Euskadi supuso un largo periodo, desde que inició la lucha armada en 1968, hasta el desarme de ETA en 2011 y su desaparición como organización armada en mayo de 2018. En este intervalo de cincuenta años, el conflicto vasco ha supuesto una serie de tensiones;la creación de un clima de inestabilidad social y de una relación tirante entre las instituciones vascas y españolas. Para el ejercicio periodístico fue un periodo difícil y de una fuerte defensa a la libertad de expresión.

En el tiempo que tuvo actividad, la organización ETA, asesinó a tres periodistas en hechos relacionados con su actividad profesional: José María Portell, director de la Hoja del lunes de Bilbao y redactor jefe de La Gaceta del Norte (28 de junio de 1978); José Luis López de Lacalle, columnista del diario El Mundo y miembro del Foro de Ermua (7 de mayo de 2000) y; Santiago Oleaga, gerente de El Diario Vasco, (5 de mayo de 2001).

Datos publicados entre 1992 y 2002, señalan que un total de 140 periodistas fueron perseguidos por ETA, al mismo tiempo que alrededor de 50 vieron amenazadas sus vidas y tuvieron que llevar escolta de seguridad durante bastantes años (Ramírez de la Piscina et al., 2016). 
Como parte de la actividad armada, la organización ETA realizó 32 atentados directos contra medios de comunicación, destacando el llevado a cabo el 30 de diciembre de 2008 contra la sede central de Euskal Irratia Telebista (EITB), en Bilbao.

En poco tiempo, en febrero de 2003 llegó nuestro turno: de un día para otro, nos cerraron Euskaldunon Egunkaria, un diario construido con el enorme esfuerzo de muchísimas personas, en el que trabajé desde su fundación en diciembre de 1990. El gran prestigio del que gozaban en la sociedad vasca no libró a los responsables y antiguos responsables del proyecto, nuestros colegas y amigos detenidos, de la incomunicación y de las sesiones de tortura. Trabajé en la sección de Política de Berria desde sus inicios. Para entonces, no solo informando de los hechos, sino también analizándolos. Era parte de mi trabajo analizar qué y por qué sucedía. No obstante, me costaba mucho entender las claves de tanta violencia (Murua, 2016, p. 7).

\section{La voz de los periodistas: violencia y ejercicio periodístico en Euskadi y México}

La propuesta de análisis se realiza en dos vertientes. Dando continuidad al contexto histórico planteado en el apartado anterior, se hace una observación del desarrollo del periodismo en el siglo XX y XXI en Euskadi y en México en el entorno de violencia, y se presentan las entrevistas como evidencia empírica del caso.

La elección de la entrevista como instrumento de investigación se basa en que, mediante la interacción cara a cara con los sujetos, se accede a la descripción que ellos llevan a cabo sobre su trabajo, las prácticas y las acciones que como profesionales del periodismo ejecutan en el entorno que se describe. De la misma manera, ayuda a cuestionar a los sujetos sobre cómo ellos perciben su práctica profesional, las reglas del juego y las violencias en contra del ejercicio periodístico.

En este sentido, las entrevistas se desarrollaron con la finalidad de conocer su actividad profesional y el trabajo que realizan, así como su experiencia dentro del periodismo, que sirve de base para indagar en lo planteado.

Se hizo una selección de cinco informantes, todos los cuales ejercen actualmente en distintos medios de información del País Vasco y de México, entrevistando a cada uno de manera independiente bajo el mismo esquema temático; al ser una entrevista semi-estructurada los temas no variaron, sin embargo, había temas en los cuales se podía profundizar dado el interés de los tópicos, o bien, de la respuestas del informante se planteaban otras preguntas a fin de encontrar puntos clave que pudieran ayudar al análisis propuesto en el trabajo. Es importante destacar la disposición de los informantes para la realización de las entrevistas bajo el planteamiento temático.

Para Martxelo Otamendi ${ }^{4}$, periodista, hoy director del diario Berria (Noticias), durante esos años era central la defensa de la libertad de expresión. La posibilidad de relatar los hechos y hacer frente a los embates contra el ejercicio periodístico. "En los años más duros del conflicto había acoso y ataques graves contra periodistas, por parte de ETA y por parte del Estado" (Otamendi, comunicación personal, 26 de abril de 2018).

El conflicto se recrudeció con la aparición de la guerra sucia y el grupo contrainsurgente Grupos Antiterroristas de Liberación (GAL) organizado y autorizado por el gobierno de España, encabezado en ese entonces por el socialista Felipe González. El diario Deia publicó en 1987 una investigación de los periodistas Ricardo Arques y Juan Carlos Urrutxurtu que denunció la trama de corrupción que organizó el GAL en el periodo comprendido entre 1983 y 1987; producto de esta investigación fue despedido el periodista Pedro J. Ramírez, director de Diario 16 en Madrid, quien por presiones del gobierno español fue relevado de su cargo.

Relata Otamendi que los GAL también ejercieron violencia contra periodistas y medios de comunicación. Atentaron contra Punto y Hora, semanario abertzale (nacionalista), asesinaron a los periodistas de Egin Xabier Galdeano y Josu Muguruza, quien también fue diputado por el partido político Herri Batasuna, también ligado a la izquierda nacionalista.

Pero quizá la agresión al ejercicio periodístico que más se ha reseñado en el periodismo vasco sea el cierre por parte del

\footnotetext{
${ }^{4}$ Entrevista realizada el 26 de abril de 2018 en las oficinas del diario Berria en Andoain, Guipozkoa.
} 
gobierno de España de los diarios Egin en 1998 y Egunkaria en 2003. En febrero de ese año

un juez de Madrid determinó cerrar y detener a los directivos del diario Euskaldunon Egunkaria (El Periódico Vasco en castellano). Este diario era desde 1990 en único periódico del País Vasco que se editaba al cien por ciento en euskera. Diez personas fueron detenidas en el mayor ataque contra la libertad de expresión por parte del gobierno central de España en contra de un medio de comunicación en los últimos años (Otamendi, comunicación personal, 26 de abril de 2018).

La falta de argumentos jurídicos y de comprobación de los hechos que se imputaban (acusaban al diario de ser controlado por ETA y a la directiva del periódico de ser miembros de la dirección de ETA) fue en gran medida lo que provocó la indignación de amplios sectores de la sociedad vasca. Entre los procesados (y torturados por cinco días) en aquellos actos se encontraba el propio director del medio. Martxelo Otamendi, quien hoy dirige Berria (Noticias en Castellano), en cuyas oficinas recibe para la entrevista. Es el mismo lugar donde se encontraba Egunkaria; es la misma oficina que la Guardia Civil española registró por más de cinco horas aquel mes de febrero de 2003.

A mí me torturaron para obtener información de las entrevistas que hice a ETA en el año 98, 99 y 2000. El escándalo internacional que provocó todo aquello fue mayúsculo: diarios y publicaciones de todo el mundo voltearon a este pequeño país (Euskadi) para dar cuenta del abuso que el Estado Español había cometido en contra de un periódico diario y periodistas en ejercicio de su profesión. La libertad de expresión es un tema sensible, como en los años más duros del conflicto: ETA mató periodistas, los GAL (grupo antiterrorista organizado por el gobierno español) también mataron periodistas, en ese periodo de más de veinticinco años, la libertad de expresión se defendía incluso con la vida (Otamendi, comunicación personal, 26 de abril de 2018).
El Tribunal Supremo dejó sin efecto el pronunciamiento relativo a la declaración de ilicitud de las actividades de Egin en 2009, sin embargo, nada se pudo hacer para reabrir el diario. Con relación al cierre de Egunkaria, los jueces declararon inocentes a todos los encausados, pero ninguno de ellos recibió indemnización por parte del Estado.

El caso que en México tiene similitudes con el cierre de Egin (1998) y Egunkaria (2003) es el de Excelsior, en 1976. A través de la cooperativa, el gobierno de Luis Echeverría Álvarez (1970 - 1976) provocó la caída del director Julio Scherer y el cierre parcial de operaciones del diario, uno de los hasta entonces, periódicos más críticos y de referencia en México. El cierre de Excelsior fue paradigmático, es el episodio que mostró las líneas más claras de la subordinación de la prensa a los poderes políticos y económicos. Se puede considerar como el primer caso de "violencia simbólica" en contra del ejercicio periodístico. Este término, recuperado de la obra de Bourdieu (2000), se puede definir como todo aquel ejercicio de control que proviene del discurso o de prácticas que contravienen el ejercicio periodístico. Bourdieu (2000), habla de cómo son naturalizadas e interiorizadas las relaciones de poder. En este caso, se hace referencia a aquella violencia que está construida y se determina en las relaciones que se constituyen al interior de los campos en los límites donde se ejerce el poder.

Por otro lado, en la violencia física contra periodistas, el caso emblemático todavía durante el régimen del PRI, es en 1984, cuando fue asesinado el periodista Manuel Buendía. Buendía escribía en las páginas de Excelsior y su homicidio se relaciona con las investigaciones que llevaba a cabo sobre los nexos que en aquellos años había entre el narcotráfico y la política. En sus últimas publicaciones, la presencia de la Drug Enforcement Administration (DEA) y la Central Intelligence Agency (CIA) en las corporaciones policiales mexicanas.

No obstante, el periodo más violento ocurrió en años posteriores al inicio de la guerra contra el narcotráfico iniciada en 2006. Como parte de la vulnerabilidad de los periodistas frente a la escalada de violencia, Hernández y Rodelo (2010) señalan como causas la inexperiencia de los periodistas para cubrir acontecimientos de seguridad pública apegándose a protocolos, la falta de apoyo de las empresas de medios a sus periodistas, la fragilidad de la profesión en México y, entre 
otras dificultades, la ausencia de suficiente análisis académico ante esta compleja problemática social.

La cobertura de los hechos de violencia por parte de periodistas en las zonas de mayor violencia o de hechos delictivos recurrentes, se lleva a cabo en condiciones precarias y sin protección alguna. Sin embargo, no son solo hechos delictivos lo que ha ocasionado que crezcan las violaciones a la libertad de expresión o la violencia contra quienes ejercen el periodismo: también es la falta de responsabilidad del Estado al quedar en el desamparo y en impunidad los crímenes. De acuerdo con el Comité de Protección a Periodistas ${ }^{5}$, de 1992 a 2017 han sido asesinados 43 periodistas, de los cuales 35 casos siguen impunes.

Pero el homicidio no es el único acto de violencia contra los periodistas en ejercicio. Artículo 19, organización internacional de vigilancia y protección de la libertad de expresión ${ }^{6}$, contabiliza por lo menos 23 reporteros desaparecidos. Para agosto de 2017 registraba 60 reportes de amenazas, 56 ataques físicos o a material de trabajo y 67 actos de intimidación.

En México, en los últimos años, el ejercicio periodístico se ha visto cada vez más coaccionado tanto por los poderes políticos como por los poderes de facto. En lo que respecta a las formas sobre cómo se relaciona el poder con el periodismo, se considera que han cambiado, según se comenta entre el gremio. El pago de la publicidad por parte de instancias gubernamentales o privadas influye en la actividad profesional del periodista al no tener él plena libertad de actuar en muchos de los casos y en donde, la empresa, determina qué se publica y qué no. "Sí influye, cómo no, porque varias de las fuentes son clientes, y aquí está el dilema claro, tengo una nota que pegue a costa de que pierda un cliente, o al revés conservo un cliente a costa de que pierda una nota que pegue" (informante3, comunicación personal, 23 de octubre de 2017).

Otro de los interrogados precisa que el ejercicio periodístico es "un periodismo basado principalmente en intereses económicos de algunos directores de medios de comunicación local, y controlados desde la administración pública a través de contratos de publicidad institucional"; sostiene y ejemplifica cómo es que se desarrollan algunos

\footnotetext{
${ }^{5}$ Ver https://cpj.org/americas/mexico/

${ }^{6}$ Fundada en 1987, tiene su sede en Londres y corresponsalías a lo largo del mundo.
}

acuerdos políticos que benefician tanto al medio como a las fuentes políticas: "yo creo que el mismo gobierno sabe con quién está trabajando, a quiénes llama y a quienes no, o con quién negocia" (informante1, comunicación personal, 26 de octubre de 2017).

Estos son ejemplos de cómo se negocia y cómo se ejercen las violencias simbólicas en el periodismo en México. Las empresas de comunicación tienen un trato muy cercano con los funcionarios de primer nivel, de acuerdo con los informantes es un hecho, los funcionarios tienen acceso directo con el gerente o el dueño del medio, con lo que la negociación se torna cupular y por lo tanto, en ocasiones el jefe de información tiene que consultar a la dirección del medio con respecto a publicar alguna información.

Esta práctica se viene realizando desde hace años, si bien ahora hay más control porque hay más medios. El entrevistado señala:

nunca es la petición explícita, yo jefe de comunicación social, yo funcionario, te invito a ti, reportero, y platicamos de todo y de nada, pero el encuentro es decirte sin decirte: cuídate de hablar mal de mí, el mensaje no es explícito, pero el hecho de que platiquemos ya supone ciertos acuerdos (informante2, comunicación personal, 24 de octubre de 2017).

La práctica periodística transita en un universo de violencias. En México se ejerce un periodismo con grandes barreras por cruzar, principalmente en el control de información que se practica actualmente desde distintas instancias. No hay un libre ejercicio de la profesión en este momento y, ¿cómo es que los campos político y económico mediante acuerdos en conjunto con las empresas de medios restringen la información que se publica?

En lo referente a las condiciones laborales, el periodista como profesional, vive una condición precaria; los salarios todavía no son lo suficientemente sólidos como para poder vivir solamente de esto. Eso refiere también a otro tipo de violencia, porque no se tienen las condiciones para sentirse protegido en este contexto; el estado violenta por lo que se escribe, las empresas fuerzan a cumplir y proteger sus intereses y los grupos criminales hostigan y amenazan por cumplir con la labor informativa. La precariedad abre la puerta 
a perfilar un periodista multifuncional que tiene que entregar notas para que se publique en diversos espacios de una sola empresa con un solo salario, e incluso realizar actividades de fotógrafo, de edición y hasta administrativas.

\section{A manera de cierre}

El momento por el que transita Euskal Herria es diferente: para empezar, no hay un contexto de violencia como el que se vivía en 2003, luego del cierre de Egunkaria. El panorama del ejercicio periodístico ha cambiado: hoy en día ya no se asesinan periodistas pero sigue habiendo, por parte del Estado o las empresas, inconformidades, molestias, por el pleno ejercicio de la libertad de expresión.

La desaparición de ETA ha llegado de manera unilateral por parte de la organización. Luego del fracaso de las negociaciones de Loiola en 2006, los directivos de ETA decidieron entregar las armas, en 2011, sin que hubiera representantes del gobierno de España. De igual manera, en mayo de 2018, en la localidad de Kambo, en la Provincia Vasca de Lapurdi (Francia), ejecutó la disolución definitiva de la organización. Es por ello que, a pesar de la disolución de ETA, el proceso no está terminado. Contrario a cómo terminan otros conflictos armados, en el caso del País Vasco no hay acuerdos de paz.

En México la coyuntura es diferente: la guerra entre los cárteles del narcotráfico, el mapa de desigualdad y la precariedad de la práctica periodística reflejan la situación del país. La perspectiva con el número de hechos de violencia no es positiva. Entre los aspectos que se deben considerar en el análisis de la violencia, están la corrupción y la impunidad, en donde el periodismo debe ser central para denunciarlos. La cobertura informativa se realiza entre amenazas y el riesgo de perder el trabajo o la vida. En un informe de The New York Times se señala que México es uno de los peores países en el mundo para ejercer el periodismo. Hasta la fecha hay registro de 104 periodistas asesinados desde el año 2000, y otros 25 están desaparecidos y, se cree, muertos ${ }^{7}$. En la lista de los lugares más mortíferos para ser reportero, México está ubicado entre Afganistán, un país devastado por la guerra, y Somalia, categorizado como Estado fallido. El año pasado

\footnotetext{
${ }^{7}$ Ver https://www.nytimes.com/es/2017/12/19/mexico-libertad-expresio $\mathrm{n}$-violencia-periodistas/
}

fueron asesinados once periodistas mexicanos, la mayor cifra durante este siglo"8.

El proceso de violencia, como en Euskal Herria, no está terminado. Los intereses económicos y políticos prevalecen coaccionando la labor informativa. Es evidente el retroceso en materia de libertad de expresión: las torturas, los asesinatos, las amenazas, la corrupción, son los ingredientes que no permiten, por un lado, analizar de manera sistemática el fenómeno ni, por el otro, plantear alternativas para solucionar de raíz el riesgo permanente que supone ejercer el periodismo en México.

Se planteaba al inicio del texto encontrar similitudes $\mathrm{u}$ divergencias en los dos contextos. Más allá de que son países que han sufrido de violencia, las condiciones de ejercicio periodístico y de libertad de expresión se han visto amenazadas en distintos momentos por factores políticos o ideológicos. Los cierres de Excelsior, Egin o Egunkaria dan cuenta de que el Estado puede hacer uso de sus recursos para evitar la circulación de publicaciones que atenten contra sus intereses.

Si bien hoy en día las condiciones en los países analizados son divergentes, en ambos casos se habla de procesos de terrorismo que no han terminado. En Euskadi el fin de la organización ETA abre un periodo de distención de la violencia que inicia con el desarme en 2011, pero que no ha supuesto un acuerdo de paz; en México los índices de violencia son crecientes y en lo referente al ejercicio periodístico suponen riesgos permanentes. La perspectiva que se comparte es la referente a la coacción económica como forma de presión a las poblaciones para intervenir en sus líneas editoriales.

En el contexto actual, se debe avanzar hacia un modelo de pleno ejercicio de las libertades que son responsabilidad de todos los miembros de una comunidad, no obstante, los factores que en ella prevalezcan. La violencia física y la violencia simbólica suponen frenos y estancamiento al pleno ejercicio de los derechos individuales y colectivos. La libertad de expresión es la libertad genuina de las democracias, en ella se debe fincar la pluralidad y el derecho al disenso. En lo particular se considera que no es con leyes como se debe hacer valer este derecho, no es un tema jurídico sino un tema

\footnotetext{
${ }^{8}$ Ver https://www.nytimes.com/es/2017/04/29/matar-periodistas-mexico -veracruz/
} 
de pleno ejercicio de libertades en Estados que suponen ser democráticos.

\section{Referencias}

Álvarez, A. (2018). Libertad de prensa y violencia en el País Vasco y Colombia. Una aproximación histórica a debates actuales. UPV-EHU (mimeo).

Bourdieu, P. (2000) Intelectuales, Política y Poder. Buenos Aires: Eudeba.

Carmena, M., Mirena, J., Múgica, R., \& Uriarte, J. M. (2013). Informe base de vulneraciones de Derechos Humanos en el caso vasco (1960-2013). Vitoria-Gasteiz: Secretaría General de Paz y Convivencia, Gobierno Vasco.

Carreño, J. (2000, marzo 1). Un modelo histórico de la relación entre prensa y poder en México en el siglo XX. Revista Mexicana de Comunicación, 62. Recuperado de http://mexicanadecomunicacion.com.mx/rmc/2000/03/ 01/un-modelo-historico-de-la-relacion-entre-prensa-y -poder-en-mexico-en-el-siglo-xx/

Díaz-Noci, J. (2012) Historia del Periodismo Vasco (16002010) Mediatika, 13.

Estornés, I. (1976). Carlismo y abolición foral: en torno a un centenario 1876-1976. Donostia: Editorial Auñamendi Argitaldaria.

Etxeberria, F., Beristain, C. M., \& Pego, L. (2017). Proyecto de investigación de la tortura y malos tratos en el País Vasco entre 1960-2014. UPV/EHU; Gobierno Vasco. Recuperado de https://www.irekia.euskadi.eus/uploads /attachments/10774/CONCLUSIONES_-_Investigaci on_tortura-malos_tratos_18-12-2017.pdf

Fuentes-Berain, R. (2001). Prensa y poder político en México. Razón y Palabra, 23. Recuperado de http://www.razony palabra.org.mx/anteriores/n23/23_rfuentes.html

García, C. (2000) La práctica periodística: herencia de cambios históricos. En Del Palacio, C. (comp.), Historia de la prensa en Iberoamérica. Guadalajara: Altexto.

Gómez, G., y Rodelo, F. (2012). Protagonismo de la violencia en los medios de comunicación. En G. Rodríguez Gómez (Ed.), La realidad social y las violencias: Zona Metropolitana de Guadalajara: diagnóstico sobre la realidad social, económica y cultural de los entornos locales para el diseño de intervenciones en materia de prevención y erradicación de la violencia (1a. ed, pp. 319-351). Ciudad de México, Tlaquepaque: INCIDE Social; CIESAS; CONAVIM; ITESO.

Hernández, M. E., \& Rodelo, F. V. (2010). Dilemas del periodismo mexicano en la cobertura de "La guerra contra el narcotráfico”: ¿Periodismo de guerra o de nota roja? En Z. Rodríguez, Entretejidos comunicacionales (193-228). Guadalajara: Universidad de Guadalajara.
Murua, I. (2016) Un final para ETA. Crónica de un proceso inacabado. Donostia: Ed. Ttarttalo.

Ramírez de la Piscina, T., Murua, I., \& Idoiaga, P. (2016). Prensa y conflicto vasco (1975-2016): Recopilatorio de actitudes y vicisitudes. Revista Latina de Comunicación Social, 71, 1007-1035.

Serna, A. M. (2014). Prensa y sociedad en las décadas revolucionarias (1910-1940). Secuencia, 88, 109 